\title{
Aqueous Chemistry Influences Uranium Isotope Fractionation
}

\author{
N. Jemison ${ }^{1}$, H. Boukhalfa ${ }^{1}$, R. MArti-ArbonA ${ }^{1 *}$, C. \\ YEAGER $^{1}$, R. WILLIAMS ${ }^{1}$, N. XU ${ }^{1}$ \\ ${ }^{1}$ Los Alamos National Laboratories, PO Box 1663 \\ *rm-a@lanl.gov
}

The uranium isotope ratio, ${ }^{238} \mathrm{U} /{ }^{235} \mathrm{U}$, can be used to better interpret environmental redox conditions. Recently, researchers have applied the ${ }^{238} \mathrm{U} /{ }^{235} \mathrm{U}$ ratio to study the formation of ore deposits, evolution of $\mathrm{O}_{2}$ levels over Earth's history, and remediation of contaminated groundwater [1]. However, to reliably apply ${ }^{238} \mathrm{U} / 235 \mathrm{U}$ to track and quantify these processes, one must recognize how variable aqueous conditions and reduction mechanics influence the uranium isotope fractionation. $\mathrm{U}(\mathrm{VI})$ reduction is the main geochemical reaction that fractionates ${ }^{238} \mathrm{U} /{ }^{235} \mathrm{U}$. Both microbial and abiotic $\mathrm{U}(\mathrm{VI})$ reduction can lead to preferential removal of ${ }^{238} \mathrm{U}$, leaving less ${ }^{238} \mathrm{U}$ in solution $[2,3,4]$. However, aqueous chemistry can strongly influence the magnitude and even direction of isotope fractionation during abiotic and microbial $\mathrm{U}(\mathrm{VI})$ reduction $[2,3,4]$. Through numerous experiments varying $U$ aqueous chemistry, we attempt to interpret several of the mechanisms controlling $\mathrm{U}$ isotope fractionation.

We conducted batch experiments investigating how aqueous chemistry influenced $U$ isotope fractionation during abiotic and microbial $\mathrm{U}(\mathrm{VI})$ reduction. Fe(II) sulfide and Shewanella (with lactate as an electron donor) were used for abiotic and microbial $\mathrm{U}(\mathrm{VI})$ reduction experiments, respectively. By varying several chemical parameters, such as $\mathrm{pH}$, bicarbonate, and $\mathrm{Ca}$ concentrations, we detected the influence of aqueous chemistry on isotope fractionation. With higher $\mathrm{pH}$ and bicarbonate and $\mathrm{Ca}$ concentrations, greater isotope fractionation was observed in both abiotic and microbial experiments. With lower levels of these constituents, muted or even reversed (preferential removal of ${ }^{235} \mathrm{U}$ ) isotope fractionation occurred. These experiments can be explained by a two-step process of either diffusion or adsorption of $\mathrm{U}(\mathrm{VI})$ to a solid surface followed by $\mathrm{U}(\mathrm{VI})$ reduction.

[1] Andersen et al. (2017) Rev. Mineral. Geochem. 82, 799-850. [2] Stylo et al. (2015) PNAS 112, 5619-5624. [3] Brown et al. (2018) PNAS 115, 8688-8693. [4] Basu et al. (2020) Envir. Sci. Technol. 54, 2295-2303. 